\title{
IMPROVING MECHANICAL PROPERTIES OF POLYSTYRENE BY ADDING GLASS FIBERS
}

\author{
MR YOUSUF PASHA SHAIK ${ }^{1} \&$ MR CHITTEM MOUNI KUMAR ${ }^{2}$ \\ ${ }^{1}$ Research Assistant, Hochschule Kaiserslautern, Germany \\ ${ }^{2}$ Product Refinement Master's Student at Hochschule Kaiserslautern Germany
}

\begin{abstract}
Selecting appropriate material for any manufacturing process is an important task for an industry. Now day's composite materials are replacing conventional materials due to their promising properties. In this study, we choose one of the composite materials made of glass fiber reinforced polystyrene to evaluate the mechanical properties and compare them. The manufacturing processes used for this process are Extrusion and Injection Molding. The idea of the project is to enhance the variation of mechanical properties by the various ratio of glass fiber in polystyrene melt. Tensile test and Charpy are the tests carried out to test the Tensile and Impact strength of the composite.

KEYWORDS: Glass Fiber, Polystyrene, Extrusion, Injection Molding, Tensile Test, Charpy, Impact Strength, Mechanical Properties
\end{abstract}

Received: Jan 07, 2021; Accepted: Jan 27, 2021; Published: Feb 05, 2021; Paper Id.: IJMPERDFEB202117

\section{INTRODUCTION}

Materials have been playing a major role in our lives throughout history. The oldest and most natural composite material is wood as it consists of cellulose fiber-reinforced in lignin matrix[1] Composite materials are firstly developed and used in 1940 when glass fiber reinforced polyester manufactured [2] According to researchers in the history, it was clear that the composite material exhibits better properties than those of individual components for example straw reinforced mud bricks, Samurai swords, and Damascus gun barrel was manufactured with a composite made of iron and steel, Bows made of cattle tendons, silk and wood, now a day's walls made of steel-reinforced concrete are constructed[3]. In the modern era use of natural fibers as reinforcement of thermoplastic polymers is mainly driven to protect the ecosystem. Natural fibers have several advantages than their inorganic compounds. Polymer blends are used because of lightweight, high elasticity, cost-effective, easy to process, and good mechanical properties [4]. In general, composites are classified as fiber-reinforced plastics (FRP) and advanced composites. FRP or fiber-reinforced composites are those polymers or plastic as matrix material and fiber as reinforcement. In general advance, composites are those in which reinforcement is more than $50 \%$ by volume. As of now, everyone is looking for materials with cost-effective and high performance with a high production rate which is not possible to obtain from a single material. So, people are choosing composites as an alternative to achieve low cost and high performance with high production rates [3].

\section{POLYSTRENE}

Polystyrene homopolymer is an amorphous, colourless, and transparent thermoplastic. It normally exhibits a brittle nature. Polystyrene is a thermoplastic material that exhibits very little heat resistance and generates crack soon. Such 
disadvantages can be overcome by the incorporation of glass fiber in polystyrene melt to some extent. It is a versatile plastic from which we can manufacture a variety of products such as solid, hard plastics; mostly it is used to manufacture products that require clarity [4].

\section{Chemistry of Polystyrene}

Polystyrene is a macromolecule made of several monomers (styrene) units. In the process of polymerization of polystyrene carbon-carbon, $\sigma$-bonds are formed attaching to another styrene monomer by breaking the carbon-carbon $\pi$-bond of a vinyl group to forms chains. As it is made of only one monomer (styrene) it can be classified as a homopolymer [5].

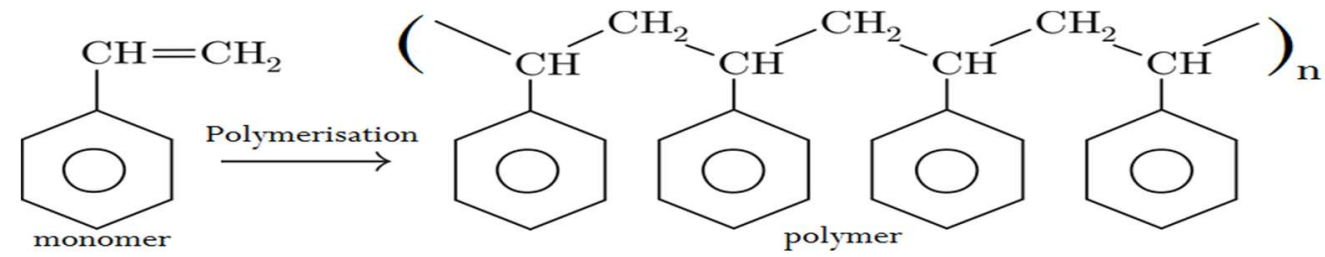

Figure 1: Polymerization of styrene

Tacticity plays a major effect on the properties of plastics. Standard polystyrene is available in amorphous which shows atactic nature in which phenyl groups are randomly distributed on both sides of the chain.
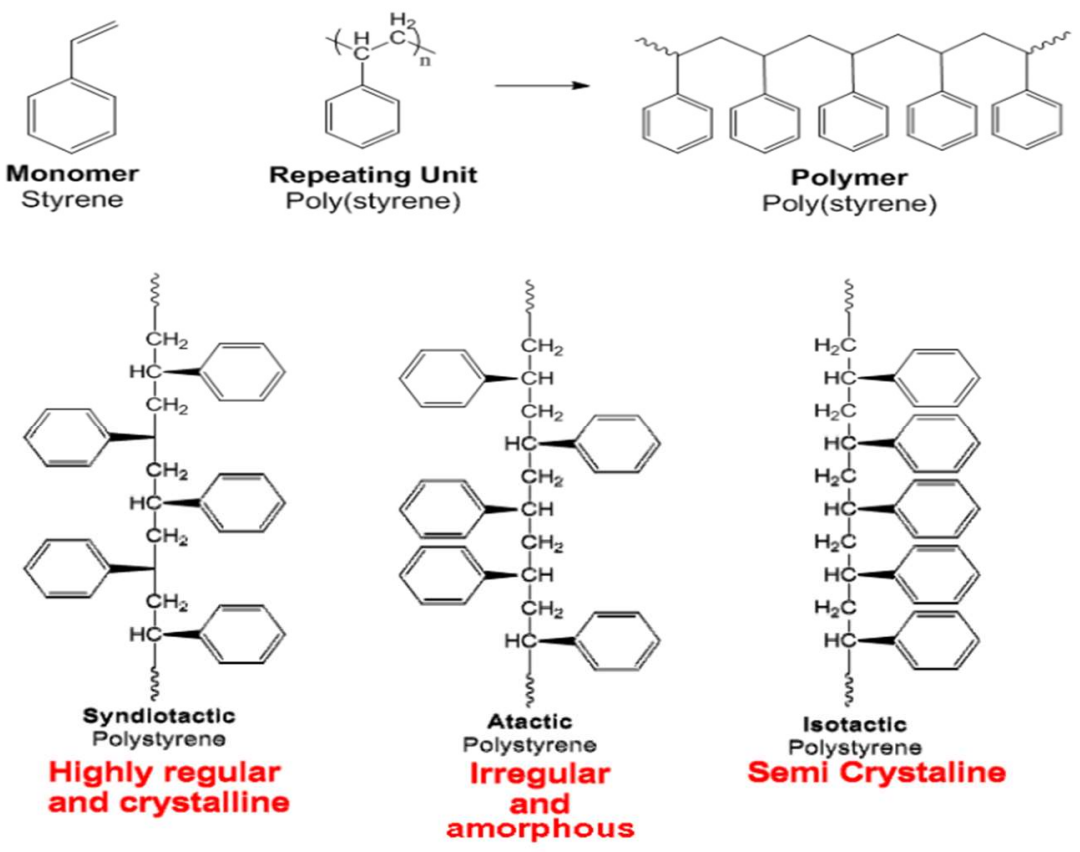

\section{COMPOSITE MANUFACTURING PROCESS}

Composite can be simply defined as a combination of two or more materials into a single material.

\section{EXTRUSION}

Extrusion is an integrated process in which polymer materials are extruded from the moulds with different shapes to produce a finished product. The line diagram of the extrusion process is shown in figure 2. Firstly, polymer received is stored and inspected then the material is blended with additives like lubricants, colour pigments, fillers, reinforcements, flame 
retardants, etc.

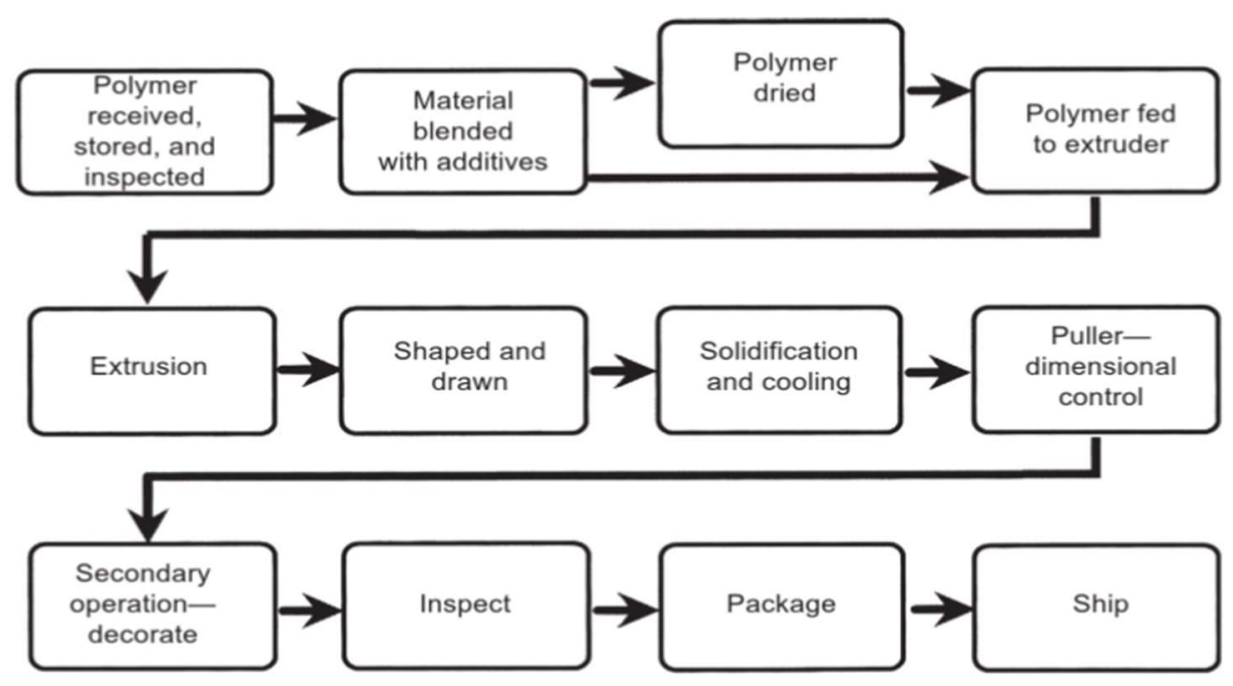

Figure 2: Schematic diagram of the extrusion process

For some materials, drying is carried out before fed to the extruder or else polymer degradation takes place due to moisture content in it. Then the polymer is fed to an extruder. The fed polymer melts and mixes with its reinforcement this melt flows through the mold to form a shape. The profile drawn is cooled to get solidified.

\section{INJECTION MOLDING}

Injection molding is a process in which helps make different parts as per the mold design by heating the plastic until it gets softened and forces into the closed mold to obtain the desired shape when cooled until it gets hardened and ejected out [6]. The injection molding is a cyclic process used for mass production of parts. It is a simple and economical.

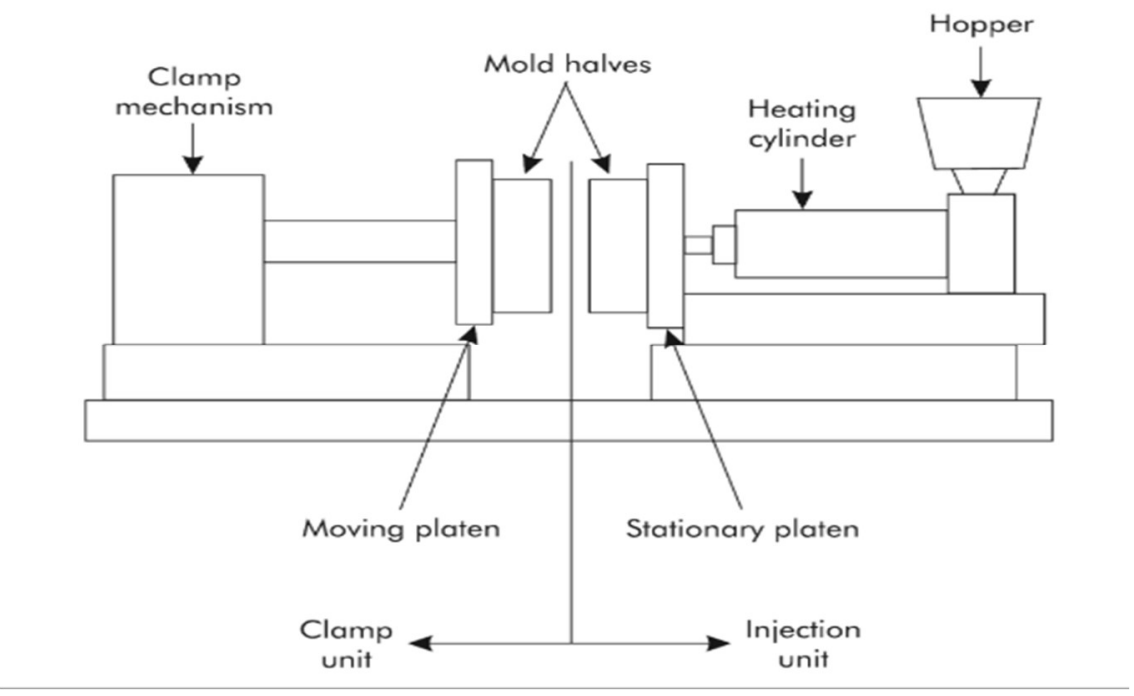

Figure 3: Injection moulding process

The polymer fed in the hopper will enter the screw or heating cylinder and get softened due to heat. The screw mixes the material into a homogeneous mixture until the perfect melt obtained. The melt is introduced to a 
closed mold to get the final product.

\section{Sample Preparation}

The pellets manufactured in the extrusion process are used in the injection moulding machine (Arburg 320S) with a temperature from $50-245^{\circ} \mathrm{C}$ with a screw diameter of $25 \mathrm{~mm}$ with a total cycle time of $30 \mathrm{ccm} / \mathrm{s}$ and holding time of $6.5 \mathrm{~s}$ also the mould plate $\mathrm{x}$ mould height $=446 \mathrm{~mm} \times 200 \mathrm{~mm}$. The length of the screw is $24 \mathrm{l} / \mathrm{d}$. These pellets were then injection moulding into standard tensile bars and flexural specimens. The total fiber contained was maintained at $0-20 \%$ wt. to manufacture dog bone samples for testing's.

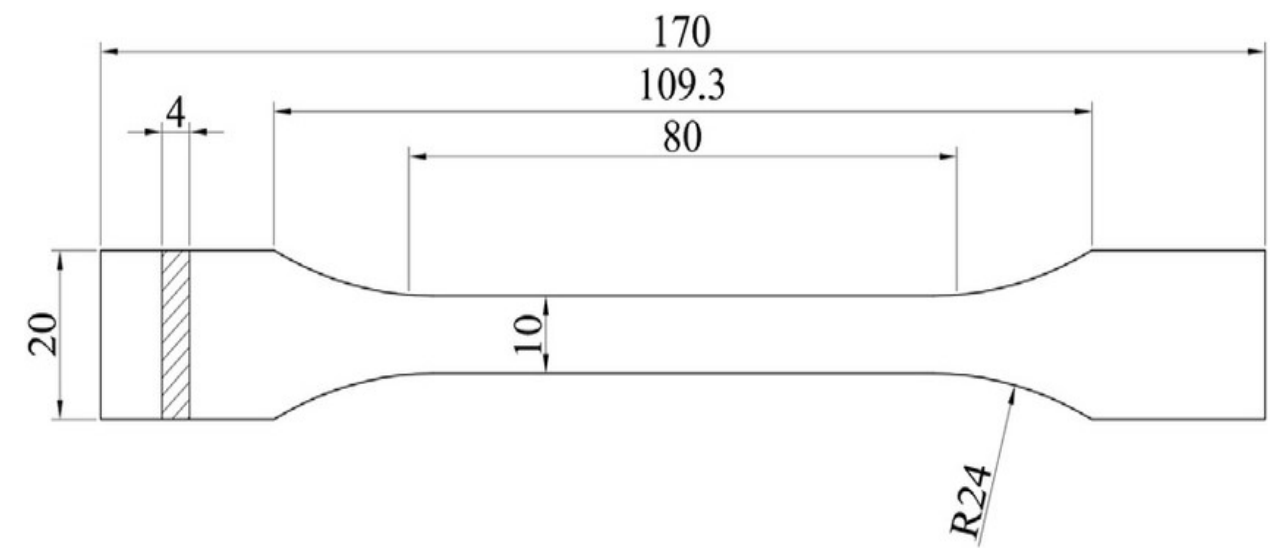

Figure 4: Dog bone sample dimensions

Injection moulding is carried out under the flow rate of $30.0 \mathrm{ccm} / \mathrm{s}$, the volume of $24 \mathrm{ccm}$, temperature starting from $50^{\circ} \mathrm{C}-245^{\circ} \mathrm{C}$ and pressure of $2200 \mathrm{bar}$. The samples are prepared using pellets obtained from grinding extruded strings.

\section{Mechanical Testing}

Tensile testing Tensile testing is conducted on the specimens using a universal tensile testing machine which is controlled electronically using a computer according to the standards DIN EN ISO 527. The specimens were deformed at a rate of $5 \mathrm{~mm} / \mathrm{min}$. The grip to grip separation at the start position is $110 \mathrm{~mm}$.

\section{Tensile Testing of $100 \%$ polystyrene}

The tensile test is carried out using three samples of polystyrene material to find out corresponding young's modulus, flexural stress and flexural strain were determined.

Table 1: Tensile test of $100 \%$ polystyrene

\begin{tabular}{|l|l|l|l|}
\hline \multicolumn{1}{|c|}{ Specimen no } & \multicolumn{1}{c|}{$\begin{array}{c}\text { Young's modulus(E) } \\
\text { MPa }\end{array}$} & $\begin{array}{c}\text { Stress(o) } \\
\text { MPa }\end{array}$ & $\begin{array}{c}\text { Strain } \\
\%\end{array}$ \\
\hline 1 & 3290 & 46.1 & 2.2 \\
\hline 2 & 3460 & 43.7 & 1.4 \\
\hline
\end{tabular}




\begin{tabular}{|l|l|l|l|}
\hline 3 & 3110 & 42.3 & 1.4 \\
\hline mean & 3290 & 44 & 1.7 \\
\hline
\end{tabular}

\section{The Stress-Strain Graph of 100\% Polystyrene}

The graph below depicts the change in stress (MPa) of the specimens with the increase in strain (\%). All the polystyrene specimens have a mean stress value of up to $44 \mathrm{MPa}$ with a $1.7 \%$ increase in strain. The stress value sharply declines after a further increase in strain value.

\section{Series graph:}

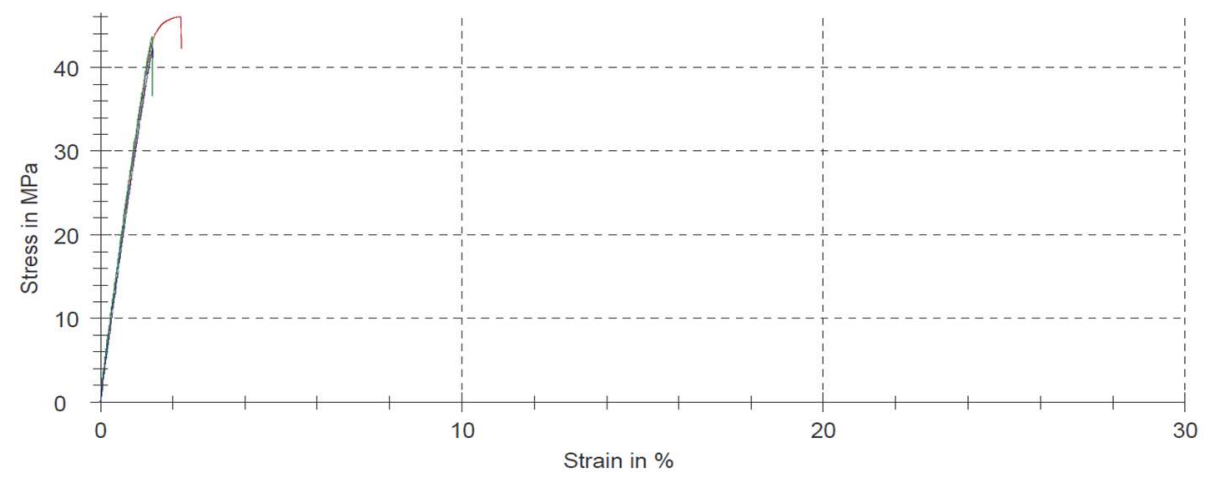

Tensile testing of $90 \%$ polystyrene and $10 \%$ glass fiber composite

The tensile test is carried out using three samples of $90 \%$ polystyrene and $10 \%$ glass fiber composite material to find out corresponding young's modulus, flexural stress and flexural strain were determined.

Table 2: Tensile test of $90 \%$ polystyrene and $10 \%$ glass fiber composite

\begin{tabular}{|c|c|c|c|}
\hline Specimen no & $\begin{array}{c}\text { Young's modulus(E) } \\
\text { MPa }\end{array}$ & $\begin{array}{c}\text { Stress( }(\sigma) \\
\text { MPa }\end{array}$ & $\begin{array}{c}\text { Strain } \\
\%\end{array}$ \\
\hline 1 & 7220 & 66.0 & 1.4 \\
\hline 2 & 4530 & 69.6 & 1.7 \\
\hline 3 & 5150 & 62.8 & 1.5 \\
\hline mean & 5630 & 66.1 & 1.5 \\
\hline
\end{tabular}

\section{The Stress-strain graph of $90 \%$ polystyrene and $10 \%$ glass fiber composite}

The graph below depicts the change in stress (MPa) of the specimens with the increase in strain (\%). All the $90 \%$ polystyrene and $10 \%$ glass fiber specimens have a mean stress value of up to $66 \mathrm{MPa}$ with a $1.5 \%$ increase in strain. The stress value sharply declines after a further increase in strain value. 


\section{Series graph:}

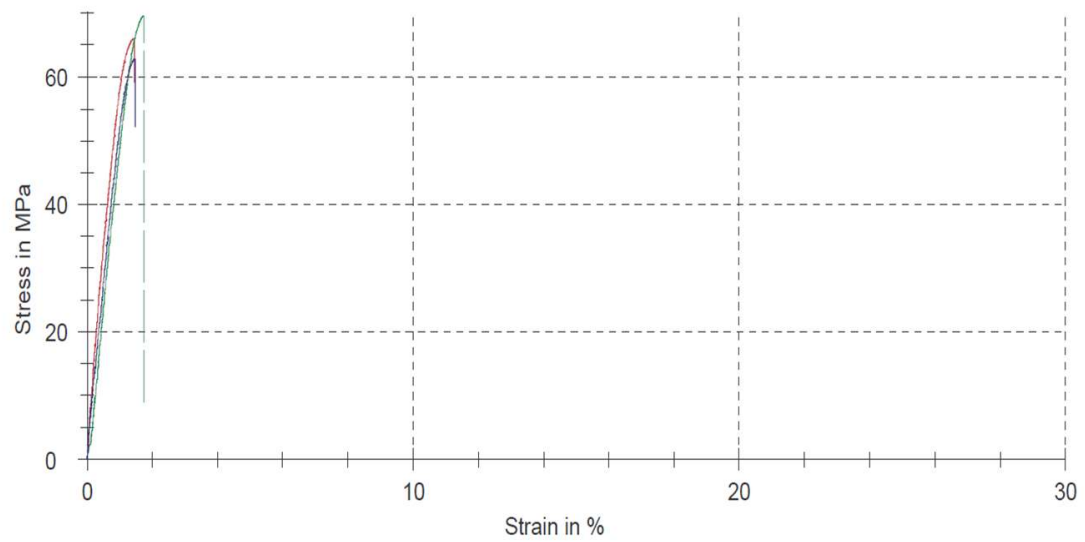

Tensile testing of $80 \%$ polystyrene and $20 \%$ glass fiber composite

The tensile test is carried out using three samples of $80 \%$ polystyrene and $20 \%$ glass fiber composite material to find out corresponding young's modulus, flexural stress and flexural strain were determined.

Table 3: Tensile test of $80 \%$ polystyrene and $20 \%$ glass fiber composite

\begin{tabular}{|c|c|c|c|}
\hline Specimen no & $\begin{array}{c}\text { Young's modulus(E) } \\
\text { MPa }\end{array}$ & $\begin{array}{c}\text { Stress( }) \\
\text { MPa }\end{array}$ & $\begin{array}{c}\text { Strain } \\
\%\end{array}$ \\
\hline 1 & 8360 & 69.7 & 1.0 \\
\hline 2 & 10600 & 70.4 & 0.87 \\
\hline 3 & 7970 & 69.3 & 1.5 \\
\hline mean & 8977 & 69.8 & 1.1 \\
\hline
\end{tabular}

The Stress-strain graph of $90 \%$ polystyrene and $10 \%$ glass fiber composite

The graph below depicts the change in stress (MPa) of the specimens with the increase in strain (\%). All the $90 \%$ polystyrene and $10 \%$ glass fiber specimens have a mean stress value of up to $69 \mathrm{MPa}$ with a $1.1 \%$ increase in strain. The stress value sharply declines after a further increase in strain value. 
Series graph:

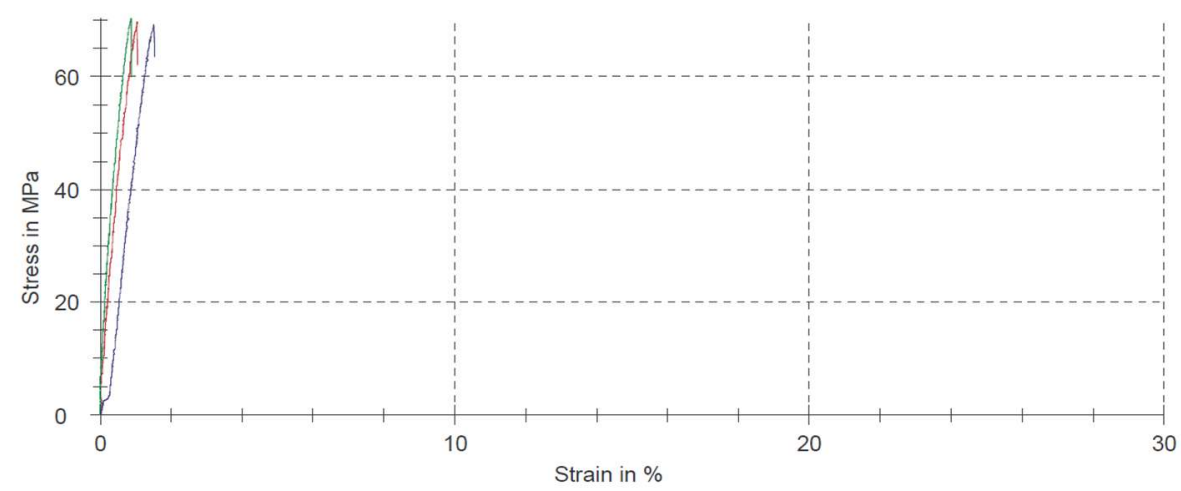

Mean and Standard Deviation of Young's Modulus

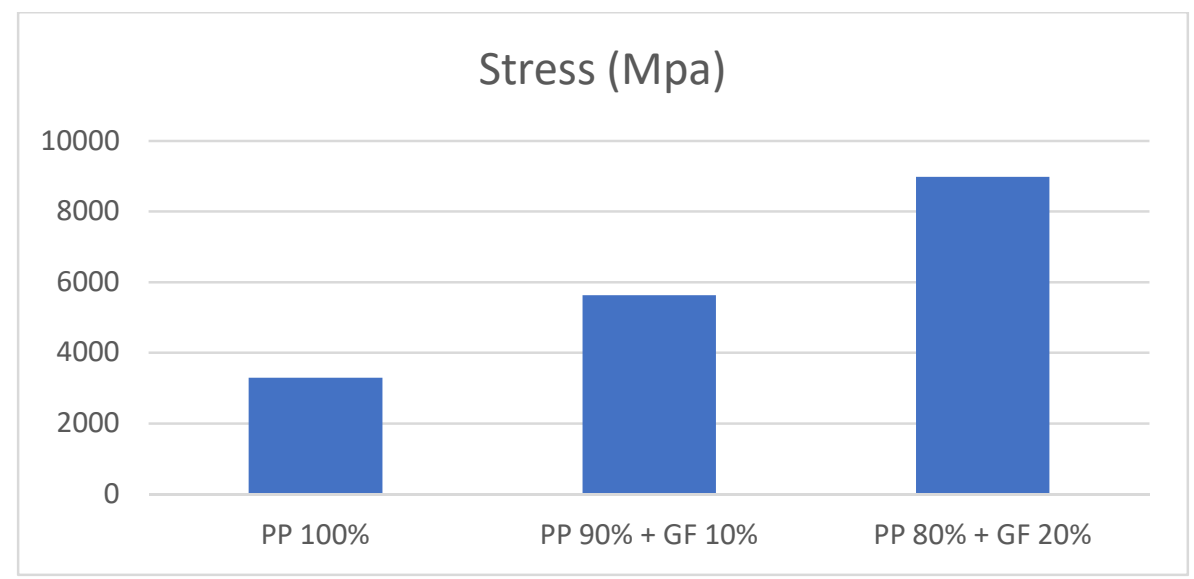

Mean and Standard Deviation of Stress

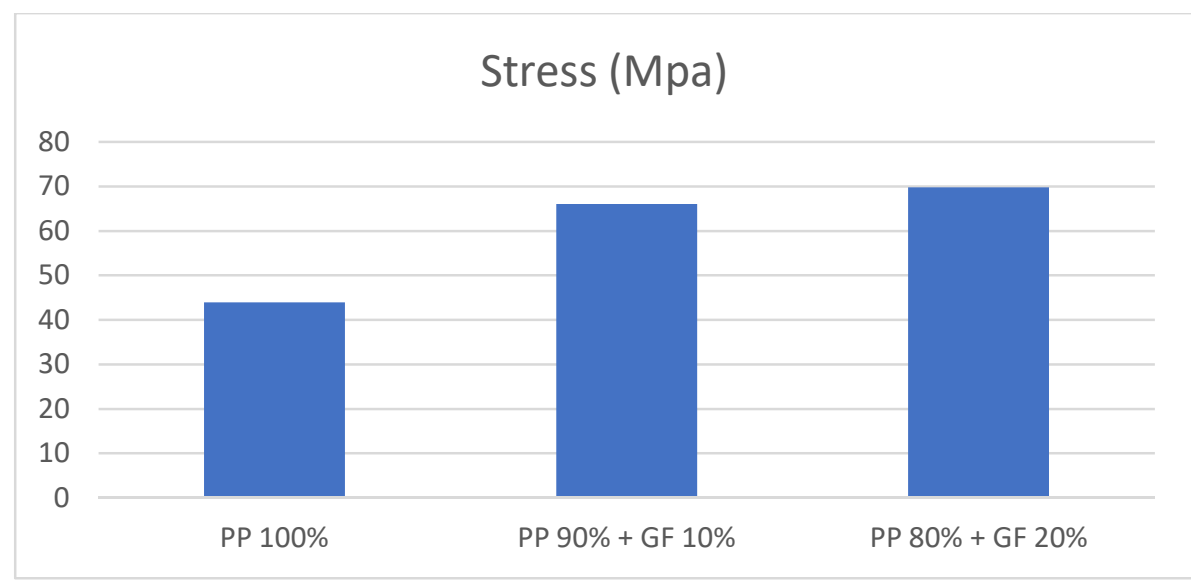

Mean and Standard Deviation of Strain 


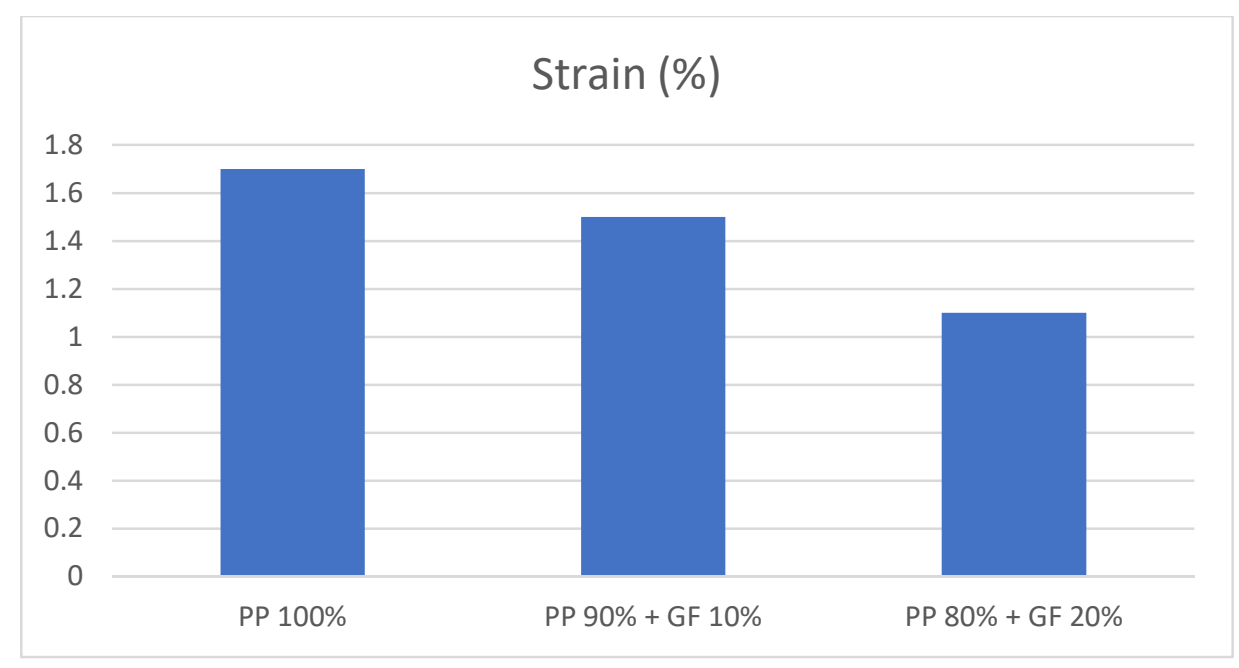

\section{Charpy Test}

The Charpy test is conducted to determine the impact properties of the material. Crack initiation and crack propagation are the basis for the changes in impact properties. Materials with good impact toughness show better performance under aggressive loading and can retain fracture for a longer period.

\section{Sample Preparation}

The dog-bone samples manufactured in injection molding are undergone some basic mechanical operations like cutting and grinding to make rectangular bars of dimensions $80 \times 10 \times 4 \mathrm{~mm}$ with a $2 \mathrm{~mm}$ notch in the middle are prepared.

\section{Experimental Procedure}

The samples are tested using under room temperature with a hammer velocity of $2.9 \mathrm{~m} / \mathrm{s}$ and a hammer of weight $1.1890 \mathrm{Kg}$. Six samples of each material are considered in which three samples with a $2 \mathrm{~mm}$ notch and the other three are without a notch are prepared. Firstly the machine is calibrated before placing the material. Once calibration is done the equipment is ready for the test. The values of the impact strength shown are noted.

\section{Impact Toughness of Polystyrene}

As mentioned in the procedure three samples of polystyrene without glass fiber are tested for impact toughness values are determined.

Table 4: Impact test of $100 \%$ polystyrene

\begin{tabular}{|l|l|l|}
\hline \multicolumn{1}{|c|}{ Sample number } & \multicolumn{1}{|c|}{ Impact energy $\mathbf{k J} / \mathbf{m}$} & \multicolumn{1}{|c|}{ Impact energy $\mathbf{k J} / \mathbf{m}^{2}$} \\
\hline $\mathbf{1}$ & 0.060 & 15.04 \\
\hline $\mathbf{2}$ & 0.063 & 15.74 \\
\hline $\mathbf{3}$ & 0.063 & 15.74 \\
\hline
\end{tabular}

With a mean standard deviation of $0.062 \mathrm{~kJ} / \mathrm{m}$ and $15.50 \mathrm{~kJ} / \mathrm{m}^{2}$ impact energy and coefficient of variation $2.607 \%$.

\section{Impact toughness of polystyrene with a notch}

As mentioned in procedure three samples with $2 \mathrm{~mm}$ notch of polystyrene without glass fiber are tested for impact toughness 
values are determined.

Table 5: Impact test of $\mathbf{1 0 0 \%}$ polystyrene without a notch

\begin{tabular}{|l|l|l|}
\hline \multicolumn{1}{|c|}{ Sample number } & \multicolumn{1}{|c|}{ Impact energy $\mathbf{k J} / \mathbf{m}$} & \multicolumn{1}{|c|}{${\text { Impact energy } \mathbf{~} \mathbf{J} / \mathbf{m}^{2}}^{\mathbf{2}}$} \\
\hline $\mathbf{1}$ & 0.005 & 1.316 \\
\hline $\mathbf{2}$ & 0.005 & 1.316 \\
\hline $\mathbf{3}$ & 0.007 & 1.755 \\
\hline
\end{tabular}

With a mean standard deviation of $0.005 \mathrm{~kJ} / \mathrm{m}$ and $1.463 \mathrm{~kJ} / \mathrm{m}^{2}$ impact energy and coefficient of variation $17.33 \%$.

Impact toughness test of $90 \%$ polystyrene and $10 \%$ glass fiber composite

As mentioned in procedure three samples of $90 \%$ polystyrene and $10 \%$ glass fiber are tested for impact toughness values are determined.

Table 6: Impact test of $90 \%$ polystyrene and $10 \%$ glass fiber composite

\begin{tabular}{|c|c|c|}
\hline Sample number & Impact energy $\mathrm{kJ} / \mathrm{m}$ & Impact energy $\mathrm{kJ} / \mathrm{m}^{2}$ \\
\hline 1 & 0.042 & 10.61 \\
\hline 2 & 0.046 & 11.68 \\
\hline 3 & 0.042 & 10.61 \\
\hline
\end{tabular}

With a mean standard deviation of $0.043 \mathrm{~kJ} / \mathrm{m}$ and $10.97 \mathrm{~kJ} / \mathrm{m}^{2}$ impact energy and coefficient of variation $5.598 \%$.

Impact toughness test of $90 \%$ polystyrene and $10 \%$ glass fiber composite with a notch

As mentioned in procedure three samples with $2 \mathrm{~mm}$ notch of $90 \%$ polystyrene and $10 \%$ glass fiber are tested for impact toughness values are determined.

Table 7: Impact test of $90 \%$ polystyrene and $10 \%$ glass fiber composite with a notch

\begin{tabular}{|l|l|l|}
\hline Sample number & Impact energy $\mathbf{k J} / \mathbf{m}$ & Impact energy $\mathbf{~} \mathbf{J} / \mathbf{m}^{\mathbf{2}}$ \\
\hline $\mathbf{1}$ & 0.012 & 3.089 \\
\hline $\mathbf{2}$ & 0.014 & 3.531 \\
\hline $\mathbf{3}$ & 0.014 & 3.531 \\
\hline
\end{tabular}

With a mean standard deviation of $0.013 \mathrm{~kJ} / \mathrm{m}$ and $3.384 \mathrm{~kJ} / \mathrm{m}^{2}$ impact energy and coefficient of variation $7.538 \%$.

Impact toughness test of $80 \%$ polystyrene and $20 \%$ glass fiber composite

As mentioned in procedure three samples of $80 \%$ polystyrene and $20 \%$ glass fiber are tested for impact toughness values are determined.

Table 8: Impact test of $80 \%$ polystyrene and $20 \%$ glass fiber composite 


\begin{tabular}{|l|l|l|}
\hline Sample number & Impact energy $\mathbf{k J} / \mathbf{m}$ & Impact energy $\mathbf{~ k J / \mathbf { m } ^ { 2 }}$ \\
\hline $\mathbf{1}$ & 0.043 & 10.97 \\
\hline $\mathbf{2}$ & 0.045 & 11.32 \\
\hline $\mathbf{3}$ & 0.039 & 9.907 \\
\hline
\end{tabular}

With a mean standard deviation of $0.042 \mathrm{~kJ} / \mathrm{m}$ and $10.73 \mathrm{~kJ} / \mathrm{m}^{2}$ impact energy and coefficient of variation $6.877 \%$.

Impact toughness test of $80 \%$ polystyrene and $20 \%$ glass fiber composite with a notch

As mentioned in procedure three samples with $2 \mathrm{~mm}$ notch of $80 \%$ polystyrene and $20 \%$ glass fiber are tested for impact toughness values are determined.

Table 9: Impact test of $80 \%$ polystyrene and $20 \%$ glass fiber composite with a notch

\begin{tabular}{|l|l|l|}
\hline \multicolumn{1}{|c|}{ Sample number } & \multicolumn{1}{|c|}{ Impact energy $\mathbf{k J} / \mathbf{m}$} & \multicolumn{1}{|c|}{ Impact energy $\mathbf{k J} / \mathbf{m}^{2}$} \\
\hline $\mathbf{1}$ & 0.017 & 4.415 \\
\hline $\mathbf{2}$ & 0.015 & 3.973 \\
\hline $\mathbf{3}$ & 0.017 & 4.415 \\
\hline
\end{tabular}

With a mean standard deviation of $0.017 \mathrm{~kJ} / \mathrm{m}$ and $4.268 \mathrm{~kJ} / \mathrm{m}^{2}$ impact energy and coefficient of variation $5.980 \%$.

Mean and Standard Deviation of Impact Strength

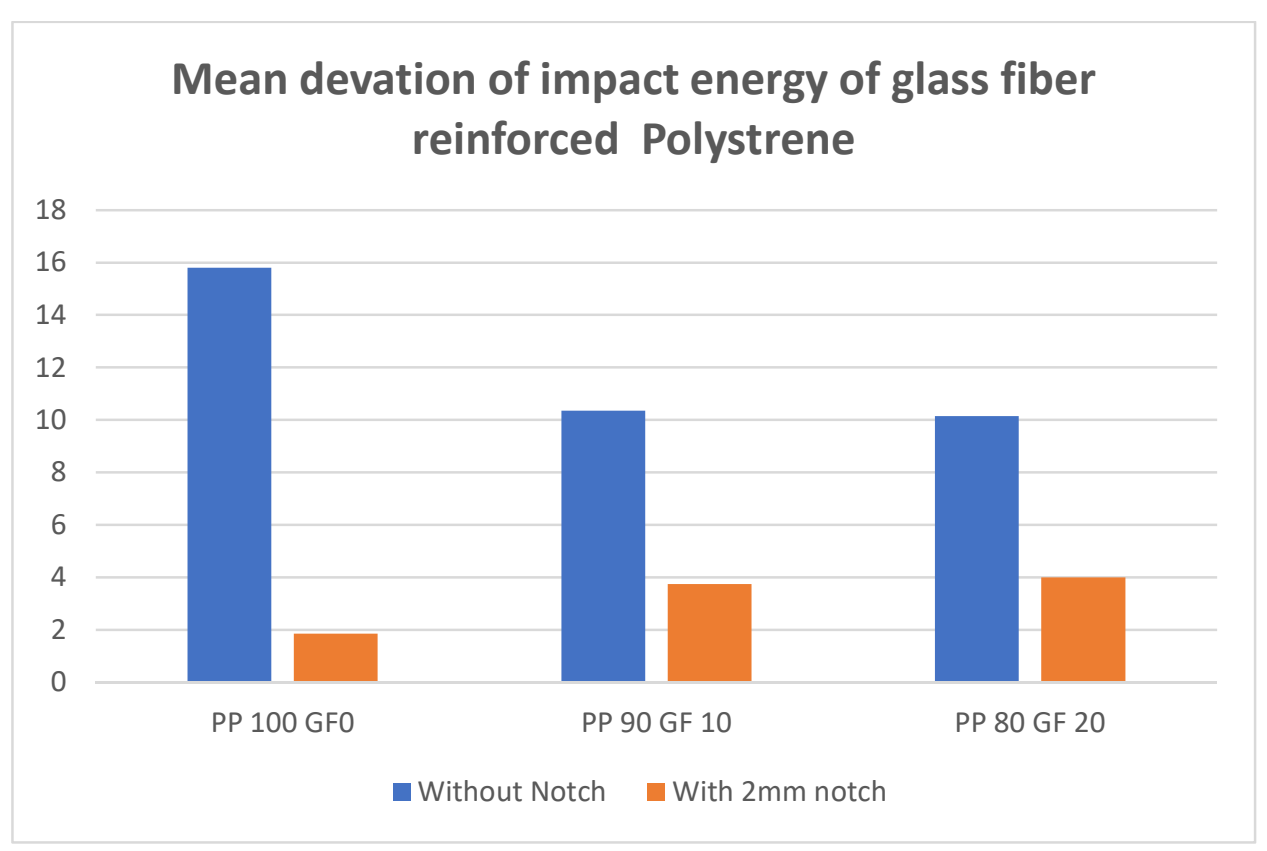

\section{CONCLUSIONS}

In this work polystyrene and glass fiber composites with different proportions are manufactured successfully and tensile and impact properties are investigated. This experiment has revealed the potentials of general-purpose polystyrene and glass fiber composites. The tensile tests have revealed that the specimen's tested shows an increasing trend of young's modulus. Among 
the manufactured composite $80 \%$ polystyrene and $20 \%$ glass fiber exhibited the best elastic behavior with a mean young's modulus of $8977 \mathrm{MPa}$. The Charpy impact tests proved that $100 \%$ polystyrene without notch exhibited the best resistance to impact with an impact resistance of $15.50 \mathrm{~kJ} / \mathrm{m}^{2}$ and $80 \%$ polystyrene and $20 \%$ glass fiber with a notch exhibited the best resistance to impact with an impact resistance of $4.415 \mathrm{~kJ} / \mathrm{m}^{2}$.

\section{REFERENCES}

1. E. J. Barbero, Introduction to Composite Materials Design, 2011.

2. Z. Z. H. Z. Jialiang Yao, Highway Engineering Composite Material and Its Application, 2019.

3. A. B. Strong, Fundamentals of Composites Manufacturing: Materials, Methods, and Applications, 1989.

4. S. J.Mishra, Micro and Nano Fibrillar Composites (MFCs and NFCs) from Polymer Blends, 2017.

5. S. N. V. KUMAR, 2017-2018. [Online]. Available: https://www.slideshare.net/SNVeereshKumar/composite-materials93861702 

